\title{
Adipokine Profile and C-Reactive Protein in Pregnancy: Effects of Glucose Challenge Response Versus Body Mass Index
}

\author{
Johan Verhaeghe, MD, PhD, Rita van Bree, MLT, Suzan Lambin, MAgrSc, and \\ Silvia Caluwaerts, $\mathrm{PhD}$
}

\begin{abstract}
OBJECTIVE: To test the hypothesis that gravidas who have an abnormal response to glucose loading have dysfunctional adipose tissue cells that produce more insulin resistance-inducing and proinflammatory adipokines but less insulin-sensitizing adipokines.

METHODS: We performed a nested case-control study within a larger sample of gravidas who had a glucose challenge test (GCT) at 24-29 weeks; we compared 73 cases with an abnormal GCT $>8.3 \mathrm{mM}$ ) and 146 controls with a strictly normal GCT $(<7.2 \mathrm{mM})$ matched for body mass index (BMI) and height (mean difference between cases and controls: $0.1 \mathrm{~kg} / \mathrm{m}^{2}$ and $1 \mathrm{~cm}$, respectively). We measured plasma insulin, adipokines (leptin, adiponectin, resistin, tumor necrosis factor [TNF]- $\alpha$, interleukin [IL]-6), soluble leptin receptor $(s \mathrm{Ob}-\mathrm{R})$, the main leptin-binding protein, and C-reactive protein (CRP).

RESULts: The cases showed a $48 \%$ increase in insulin concentrations and a $27 \%$ increase in TNF- $\alpha$ concentrations compared to the controls (both $\mathrm{P}<.0001$ ), but leptin, sOb-R, IL-6, and adiponectin, as well as CRP, concentrations were comparable between cases and controls. In the whole group $(\mathrm{n}=219)$, $B M I$ was correlated with insulin, leptin, IL-6, and CRP, and inversely with $s O b-R$ and adiponectin concentrations (all $\mathrm{P}<.0003$ ).

Conclusions: Plasma leptin, $s O b-R, I L-6$, and adiponectin, as well as CRP, are strongly related to $B M I$ in gravidas at 24-29 weeks gestational age but not to the glucose loading response. However, TNF- $\alpha$ is higher in women with an abnormal GCT. Further studies should disclose the source of increased TNF- $\alpha$ in these women, and to assess whether TNF- $\alpha$ is causally related to glucose intolerance during pregnancy. (J Soc Gynecol Investig 2005;12:330-4) Copyright (C) 2005 by the Society for Gynecologic Investigation.
\end{abstract}

KeY wORDS: Adipokines, C-reactive protein, glucose challenge test, soluble leptin receptor, tumor necrosis factor- $\alpha$.

B eing overweight is a prime risk factor for the development of gestational diabetes mellitus (GDM). ${ }^{1}$ It is now recognized that adipose tissue is an active player in the regulation of insulin sensitivity. Adipose tissue cells secrete a number of hormones and cytokines, known as adipo(cyto) kines, which include leptin, adiponectin, resistin, tumor necrosis factor(TNF)- $\alpha$, and interleukin (IL)-6. Evidence is accumulating that individuals at risk for glucose intolerance have dysfunctional fat cells, which produce excessive amounts of insulin resistance-inducing and/or proinflammatory adipokines (resistin, TNF- $\alpha$, IL-6, leptin) but less insulin-sensitizing, anti-inflammatory adipokines (adiponectin). ${ }^{2}$ In animal models, a surge in circulating resistin, ${ }^{3} \mathrm{TNF}-\alpha,{ }^{4}$ or IL- $6^{5}$ induces

From the Department of Obstetrics and Gynecology, Katholieke Universiteit Leuven, Leuven, Belgium.

S. Lambin and this work were supported by grants from the Fonds voor Wetenschappelijk Onderzoek-Vlaanderen (Belgium) (grant G.0221.03) and the Katholieke Universiteit Leuven (Onderzoekstoelage OT/02/48).

Address correspondence and reprint requests to: Johan Verhaeghe, MD, PhD, Department of Obstetrics and Gynecology, U.Z. Gasthuisberg, Herestraat 49, 3000 Leuven, Belgium. E-mail: johan.verhaeghe@uz.kuleuven.ac.be

Copyright (C) 2005 by the Society for Gynecologic Investigation. Published by Elsevier Inc. insulin resistance, whereas elevated circulating adiponectin ameliorates insulin sensitivity. ${ }^{6}$ Although leptin may also modulate insulin sensitivity, ${ }^{2}$ most overweight individuals are resistant to the effects of leptin. Several adipokines (TNF- $\alpha$, IL-6, leptin, and perhaps resistin) up-regulate the secretion of acute-phase proteins, such as $\mathrm{C}$-reactive protein (CRP), and insulin resistance has been linked to chronic inflammation. ${ }^{2}$

During normal pregnancy, circulating TNF- $\alpha^{7}$ and leptin ${ }^{8}$ rise, as does the soluble leptin receptor (sOb-R), ${ }^{9}$ which serves as the main leptin-binding protein. ${ }^{10}$ Like obesity, pregnancy is accompanied by hypothalamic leptin resistance. ${ }^{11}$ Alterations in adipokine concentrations may be implicated in the development of glucose intolerance during pregnancy. In effect, the rise in circulating TNF- $\alpha$ during pregnancy was correlated with the decline in insulin sensitivity, ${ }^{7}$ and glucose-intolerant gravidas were found to have higher plasma leptin ${ }^{12}$ but lower adiponectin ${ }^{13}$ concentrations than gravidas with normal glucose tolerance. However, serum CRP appeared to be unaffected by the glucose tolerance status of gravidas. ${ }^{14}$ 
Table 1. Clinical Data of the Sample

\begin{tabular}{|c|c|c|c|}
\hline & $\begin{array}{c}\text { Cases } \\
\left(n=73^{*}\right)\end{array}$ & $\begin{array}{c}\text { Controls } \\
\left(n=146^{*}\right)\end{array}$ & $P$ value \\
\hline \multicolumn{4}{|l|}{ Predefined criteria } \\
\hline Height $(\mathrm{cm})^{\dagger}$ & $165(6)$ & $165(5)$ & $.99^{\ddagger}$ \\
\hline $\mathrm{BW}$ at $\mathrm{GCT}(\mathrm{kg})^{\dagger}$ & $74.2(11.3)$ & $74.1(10.9)$ & $.98^{\ddagger}$ \\
\hline BMI at GCT $\left(\mathrm{kg} / \mathrm{m}^{2}\right)^{\dagger}$ & $27.1(3.9)$ & $27.1(3.9)$ & $.97^{\ddagger}$ \\
\hline Parity $(0 / 1 / 2 />2)(\%)$ & $48 / 29 / 16 / 7$ & $51 / 27 / 18 / 4$ & $.83^{\S}$ \\
\hline Smoking (no/yes) $(\%)$ & $89 / 11$ & $92 / 8$ & $.40^{\S}$ \\
\hline Gestational age at GCT (wk) ${ }^{\dagger}$ & $26.2(1.6)$ & $26.1(1.6)$ & $.67^{\ddagger}$ \\
\hline \multicolumn{4}{|l|}{ Pregnancy outcome } \\
\hline Weight gain/wk $(\mathrm{g})^{\dagger}$ & $408(148)(n=58)$ & $472(163)(n=116)$ & $.03^{\ddagger}$ \\
\hline Hypertension (no/yes) (\%) & $68 / 32(n=72)$ & $77 / 23$ & $.17^{\S}$ \\
\hline
\end{tabular}

* Unless stated otherwise.

† Data are shown as means (SD).

‡ Two-sample test.

$\$$ Chi-square statistics.

In the current study, we assessed whether gravidas with an abnormal response to a glucose challenge show an altered profile of circulating adipokines and higher CRP concentrations than gravidas with a normal glucose challenge response matched for both weight and height. Indeed, because many women with GDM are overweight, careful matching for body weight is mandatory. We also matched for height, because low stature has been shown to be an independent risk factor for GDM in several populations. ${ }^{15,16}$

\section{SUBJECTS AND METHODS}

\section{Subjects}

The study protocol was approved by the Ethical Committee of the Faculty of Medicine. We performed a nested case-control study within the Leuven-GCT database, which consists of 800 women who donated, after informed consent, an extra blood sample at the time of their GCT, between 24 and 29 weeks gestational age, ordered by their obstetrician/gynecologist. Entry criteria were: white race and self-claimed Belgian (or Dutch) ancestry, and a singleton pregnancy. A venous blood sample was withdrawn 60 minutes after ingesting $100 \mathrm{~mL}$ of a $50 \%$ glucose solution; in the meantime, patients were requested not to eat, drink, chew gum, or smoke, and not to walk about. GCTs occurred throughout the day (between $9 \mathrm{Am}$ and $8 \mathrm{PM}$ ), in the fasting or (in the large majority) nonfasting state. Samples were kept at $4 \mathrm{C}$, centrifuged on a twice-daily basis, aliquoted, and stored at $-80 \mathrm{C}$.

On the basis of the post-GCT plasma glucose concentration as per study protocol (the glucose value obtained for clinical purpose was not taken into account), three groups were defined: normal (GCT $<7.2 \mathrm{mM},<130 \mathrm{mg} / \mathrm{dL})(n=613)$, equivocal $(7.2-8.3 \mathrm{mM})(n=111)$, and abnormal $(>8.3 \mathrm{mM}$, $\geq 150 \mathrm{mg} / \mathrm{dL})(n=76)$. The "equivocal" group reflects the ongoing, unresolved debate on what is the optimal cut-off value for the GCT in the screening of GDM: $7.2 \mathrm{mM}$ is the strictest threshold, and $8.3 \mathrm{mM}$ the least strict. ${ }^{17}$ Therefore, in the present study, we did not include gravidas with an equivocal GCT result. We aimed to match each of the 76 gravidas with an abnormal GCT (cases) with two gravidas with a normal GCT (controls) for both body mass index (BMI) at the time of the GCT and height (and, hence, body weight). But for three case gravidas with a BMI $>40(42.1,42.8$, and $47.1 \mathrm{~kg} /$ $\mathrm{m}^{2}$ ), we did not find appropriate controls; thus, the final sample consisted of 73 cases and 146 controls. The mean difference in BMI between controls and the respective case was $0.11 \mathrm{~kg} / \mathrm{m}^{2}$ (SD 0.13, range $0-0.74 ; n=146$ ); the mean difference in height was $1.26 \mathrm{~cm}$ (SD 1.14, range 0-7); the BMI of the cases varied between 19.9 and $35.5 \mathrm{~kg} / \mathrm{m}^{2}$.

There was no interference with subsequent clinical management, and clinical data were retrieved from patient files after delivery. Height at booking was recorded, as well as body

Table 2. Insulin Concentrations at the GCT, Adipokine Profile, and CRP Concentrations

\begin{tabular}{lccc}
\hline & $\begin{array}{c}\text { Cases } \\
(\boldsymbol{n}=\mathbf{7 3})^{*}\end{array}$ & $\begin{array}{c}\text { Controls } \\
(\boldsymbol{n}=\mathbf{1 4 6})\end{array}$ & $\boldsymbol{P}$ value $^{\boldsymbol{*}}$ \\
\hline Insulin (pM) & $1036(583)$ & $702(480)$ & $<.0001$ \\
Adipokines & & & \\
$\quad$ Leptin (nM) & $1.18(0.46)$ & $1.26(0.56)$ & .55 \\
sOb-R (U/mL) & $33.4(15.3)$ & $36.0(17.7)$ & .42 \\
Free leptin index & $1.57(1.17)$ & $1.65(1.53)$ & .81 \\
Adiponectin (pM) & $538(356)$ & $556(229)$ & .10 \\
Resistin (pM) & $658(156)$ & $633(143)$ & .24 \\
TNF- $\alpha(\mathrm{pg} / \mathrm{mL})$ & $4.66(3.17)$ & $3.68(3.84)$ & $<.0001$ \\
$\quad$ IL-6 (pg/mL) & $1.02(0.79)$ & $0.94(0.62)$ & .42 \\
CRP (mg/L) & $5.30(4.10)$ & $5.56(5.21)$ & .84 \\
\hline
\end{tabular}

Conversion factors of SI units to conventional units: insulin, $1000 \mathrm{pM}=167 \mu \mathrm{U} / \mathrm{mL}$; leptin, $1 \mathrm{nM}=16 \mathrm{ng} / \mathrm{mL}$; adiponectin, $100 \mathrm{pM}=3 \mathrm{ng} / \mathrm{mL}$; resistin, $100 \mathrm{pM}=1.25$ $\mathrm{ng} / \mathrm{mL}$.

* Data are shown as means (SD).

† Two-sample test. 
Table 3. Spearman Rank Correlation Coefficients, Controlled for Age, Between BMI and Plasma Glucose, Insulin, Adipokine, and CRP Concentrations $(N=219)$

\begin{tabular}{lrrr}
\hline & BMI & Glucose & \multicolumn{1}{c}{ Insulin* } \\
\hline Insulin* & $0.35(P<.0001)$ & $0.51(P<.0001)$ & - \\
Leptin & $0.68(P<.0001)$ & $\mathrm{NS}$ & $0.32(P<.0001)$ \\
sOb-R & $-0.54(P<.0001)$ & $\mathrm{NS}$ & $-0.28(P<.0001)$ \\
Free leptin index & $0.67(P<.0001)$ & $\mathrm{NS}$ & $0.33(P<.0001)$ \\
Adiponectin & $-0.25(P=.0002)$ & $\mathrm{NS}$ & $-0.27(P<.0001)$ \\
Resistin & $\mathrm{NS}$ & $\mathrm{NS}$ & $\mathrm{NS}$ \\
TNF- $\alpha$ & $\mathrm{NS}$ & $0.23(P=.0008)$ & $0.13(P=.05)$ \\
IL-6 & $0.34(P<.0001)$ & $\mathrm{NS}$ & $0.28(P<.0001)$ \\
CRP & $0.25(P=.0002)$ & $\mathrm{NS}$ & $0.20(P=.004)$ \\
\hline
\end{tabular}

NS $=$ not significant

${ }^{*} \log _{10}$ values were used for correlations, because of unequal variance.

weight at booking, at the GCT, and at the last visit. Weight change during pregnancy was calculated as the change in body weight from the booking visit to the last visit, and weekly weight change as weight change divided by the number of weeks over which the weight change had occurred. Hypertension was defined as a diastolic blood pressure $\geq 90 \mathrm{mmHg}$ on two or more occasions at least 4 hours apart. ${ }^{18}$ From the files, it appeared that 43 cases had completed a $100-\mathrm{g}$ oral glucose tolerance test (OGTT); 14 cases but none of the controls had been prescribed dietary treatment by their physician, and 1 case had been prescribed insulin as well.

\section{Plasma Assays}

Glucose was assayed by the glucose-oxidase method with a YSI 2300 Stat Plus glucometer (YSI Inc, Yellow Springs, OH); within-assay coefficient of variation $(\mathrm{CV})$ is $1.2 \%$. Insulin was measured by radioimmunoassay, with recombinant human insulin as the standard, and a rabbit polyclonal antiserum; the detection limit is $15 \mathrm{pM}$, and within- and between-assay CV is $3.2-5.9 \% .{ }^{19}$ Leptin and adiponectin were measured by radioimmunoassay kits using rabbit polyclonal antisera (Linco Research, St. Charles, MO); within- and between-assay CV is less than $8.4 \%$ for the leptin assay and less than $9.3 \%$ for the adiponectin assay. sOb-R and resistin were measured by enzyme immunoassay kits purchased from BioVendor Laboratory Medicine, Brno, Czech Republic. In the sOb-R assay, a monoclonal anti-human leptin receptor antibody is used; the detection limit is $0.4 \mathrm{U} / \mathrm{mL}$ (equivalent to $0.8 \mathrm{ng} / \mathrm{mL}$ ), and within- and between-assay CV is less than $6.4 \%$. In the resistin assay, a rabbit polyclonal antiserum is used, and within- and between-assay $\mathrm{CV}$ is less than $5.5 \%$; this assay has been validated previously. ${ }^{20}$ TNF- $\alpha$ and IL-6 were measured by enzyme immunoassay kits (Quantikine High Sensitivity) from R\&D Systems Europe, Abingdon, UK; within-assay CV is less than $8.9 \%$ and between-assay CV less than $16.8 \%$ for the TNF- $\alpha$ assay, and less than $7.9 \%$ and less than $9.7 \%$, respectively, for the IL-6 assay. High-sensitivity CRP was measured by enzyme immunoassay kits from Alpha Diagnostic International, San Antonio, TX, with a detection limit of $0.35 \mu \mathrm{g} / \mathrm{L}$, and within- and between- assay CV $\leq 7 \%$; samples with CRP greater than $10 \mathrm{mg} / \mathrm{L}$ were serially diluted.

Data analysis was performed using the NCSS software, version 2004 (Kaysville, UT). For comparisons of numerical data, we checked the data for normality and variance, and used the appropriate two-sample test (equal-variance $t$ test, unequalvariance $t$ test, Wilcoxon rank-sum test, Kolmogorov-Smirnov test). For comparisons of categorical data (parity, smoking status, hypertension, genotype distribution), we used the $\chi^{2}$ test. Correlation matrices were examined using Spearman-rank pair-wise correlation.

\section{RESULTS}

The cases (abnormal GCT) and controls (normal GCT) were well matched for height, weight, and BMI (Table 1); of the 73 cases, 19 gravidas had a BMI greater than 30, 29 had a BMI between 25 and 29.9, and 25 had a BMI less than $25 \mathrm{~kg} / \mathrm{m}^{2}$. There was no difference in parity or in smoking status between cases and controls, and the gestational age at the GCT was comparable; the time (h) at GCT was recorded in 188 women, and was also comparable $(P=.40)$ between cases $(n=65)$ and controls. However, the age of gravidas with an abnormal GCT was higher than those with a normal GCT. The pregnancy outcome was comparable in cases and controls, with no difference in the incidence of hypertension, or birth weight, length $(P=.57)$, and placental weight. Weight gain during pregnancy was slightly lower in women with an abnormal GCT.

Table 2 shows that post-GCT insulin concentrations were increased in women with an abnormal GCT. However, the insulin:glucose ratio was normal $(P=.35)$. Regarding the adipokines, the only difference between cases and controls was a $27 \%$ increase in plasma TNF- $\alpha$ in women with an abnormal GCT.

The BMI at the time of the GCT was positively correlated with plasma insulin, leptin, IL-6, and CRP concentrations, and negatively with sOB-R and adiponectin concentrations (Table 3). Of the adipokines, only plasma TNF- $\alpha$ was correlated with glucose concentrations. PostGCT insulin was correlated with leptin, TNF- $\alpha$, IL-6, and CRP concentrations, and inversely correlated with $s \mathrm{Ob}-\mathrm{R}$ and adiponectin concentrations.

\section{DISCUSSION}

The cases and controls were matched for body weight and height, and also for race/ancestry, parity, smoking status, number of fetuses, and gestational age and time at blood sampling. 
Weight, height, ethnicity, number of fetuses, and perhaps smoking status are known to affect glucose tolerance during pregnancy. ${ }^{1,15,16}$ However, we have no data on fat mass distribution and leg-to-height ratio, which may offer a better prediction of GDM risk than do BMI and height, respectively. ${ }^{21,22}$ There was a 2 -year difference in mean age, and a 1 -year (31 vs. 30 years) difference in median age, between cases and controls. Age is another risk factor of GDM, ${ }^{1}$ but the small difference in mean/median age is unlikely to impact adipokine and CRP concentrations.

The adipokine profile was comparable between cases and controls, except for TNF- $\alpha$, which was $27 \%$ higher in gravidas with an abnormal GCT. During pregnancy, TNF- $\alpha$ is produced not only by adipose tissue, but also by the decidua and placenta. ${ }^{23}$ Coughlan et al found that the ex vivo TNF- $\alpha$ release by adipose tissue and placenta from women with GDM was lower than in controls at normal glucose concentrations (5 $\mathrm{mM}$ ) but was stimulated to a higher extent at hyperglycemic conditions $(15-25 \mathrm{mM}) \cdot{ }^{24}$ Recently, the placental gene profile was assessed by microarray in gravidas with GDM, who also had increased plasma TNF- $\alpha$ concentrations. ${ }^{25}$ While the TNF- $\alpha$ gene expression was normal in GDM placentas, the TNF receptor expression was up-regulated 18 -fold, and the TNF- $\alpha$-induced CG-12 protein threefold compared to control placentas. Hence, the source of increased circulating TNF- $\alpha$ in gravidas with decreased glucose tolerance requires further investigation. It is also unclear whether increased TNF- $\alpha$ is causally related to the development of glucose intolerance, or is secondary to the relative hyperglycemia or/ and hyperinsulinemia. The finding that the rise in TNF- $\alpha$ during pregnancy is related to the development of insulin resistance favors the former hypothesis ${ }^{7}$; on the other hand, hyperinsulinemia in healthy young adults produced a twofold stimulation of TNF- $\alpha$ gene expression in subcutaneous adipose tissue. ${ }^{26}$

If the data from case and control gravidas were combined, plasma leptin was correlated with BMI and insulin concentrations, as predicted. ${ }^{19}$ In contrast, concentrations of sOb-R, the main leptin-binding protein, were inversely correlated with BMI and circulating insulin and leptin, in line with data in nonpregnant women. ${ }^{27,28}$ However, sOb-R concentrations were comparable between case and control gravidas. It has been proposed that sOb-R levels are a marker of leptin sensitivity/resistance ${ }^{28}$; if so, our data suggest that leptin resistance is unlikely to be of pathogenic importance in gestational glucose intolerance.

IL-6 and CRP concentrations were also comparable between cases and controls, and were correlated with BMI and post-GCT insulin concentrations. IL-6 was previously shown to be correlated with BMI in nondiabetic or diabetic men and nonpregnant women, ${ }^{26,29,30}$ but the relation of IL- 6 to insulin sensitivity in humans is controversial at this time. ${ }^{29,30}$ Our CRP data confirm previous findings showing a correlation between BMI and CRP levels in a multi-ethnic sample of glucose-tolerant and -intolerant gravidas, whereas there was no effect of glucose tolerance status. ${ }^{14}$ In nonpregnant nondiabetic women, CRP correlates with both fasting insulin and glucose levels. ${ }^{31,32}$ We found that plasma IL-6, but not TNF- $\alpha$, was correlated with CRP $(R=0.41, P<.0001)$, corroborating the concept that fat mass drives IL-6 secretion, which in turn up-regulates CRP secretion. ${ }^{2,32}$

Resistin concentrations were not correlated with either BMI or insulin levels in this pregnant sample. Although a correlation between circulating resistin and $\mathrm{BMI}^{33}$ or fat mass $^{34}$ was documented in some nonpregnant populations, there was no such relation in other cohorts ${ }^{20,35}$; in addition, in contrast to rodent models, ${ }^{3}$ the association between circulating resistin and insulin resistance appears to be weak or absent in humans. ${ }^{34,35}$ Here, we found no difference in adiponectin concentrations between cases and controls, which is at odds with reported data. ${ }^{13}$ In another recent study, plasma adiponectin 3 months after delivery was lower-while leptin, IL-6, and CRP concentrations were higher-in women who had developed GDM during pregnancy than in controls; after correcting for fat mass, the difference in adiponectin (but not leptin, IL-6, and CRP) between the two groups persisted. ${ }^{36}$

The main limitation of the present study is that we did not perform OGTTs to confirm abnormal and normal glucose tolerance in cases and controls, respectively. On the other hand, it is well appreciated that glucose tolerance/intolerance during pregnancy is a continuum; importantly, we excluded gravidas with an equivocal GCT result $(7.2-8.3 \mathrm{mM})$. On the basis of data from the Toronto GDM-project, ${ }^{17}$ we calculated that two of the 146 controls might have been glucose-intolerant by OGTT. Indeed, if $7.3 \mathrm{mM}$ was defined as the cut-off value of the GCT, and the Carpenter-Coustan OGTT criteria were used for the diagnosis of GDM, then only $1.4 \%$ of 4254 gravidas were misclassified as having normal glucose tolerance. In contrast, the large majority of women with post-GCT glucose greater than $8.3 \mathrm{mM}$ would be expected to be glucoseintolerant by OGTT. In the Toronto GDM-project, $8.3 \mathrm{mM}$ was the highest acceptable cut-off value for the GCT in a screening approach using variable thresholds according to time since last meal; here, we used the $8.3 \mathrm{mM}$ threshold irrespective of time since last meal.

In conclusion, plasma concentrations of several adipokines (leptin, adiponectin, IL-6), sOb-R, and CRP, measured in 219 gravidas at 24-29 weeks gestational age, were strongly related to BMI, but were comparable in two subgroups with a markedly different response to a glucose challenge. TNF- $\alpha$, however, was higher in women with an abnormal glucose challenge response. Further studies are needed to establish whether the relationship between increased TNF- $\alpha$ and glucose tolerance during pregnancy is causative rather than secondary.

\section{REFERENCES}

1. Solomon CG, Willett WC, Carey VJ, et al. A prospective study of pregravid determinants of gestational diabetes mellitus. JAMA 1997;278:1078-83.

2. Bays H, Mandarino L, DeFronzo RA. Role of the adipocyte, free fatty acids, and ectopic fat in pathogenesis of type 2 diabetes 
mellitus: peroxisomal proliferator-activated receptor agonists provide a rational therapeutic approach. J Clin Endocrinol Metab 2004;89:463-78.

3. Satoh H, Nguyen MTA, Miles PDG, Imamura T, Usui I, Olefsky JM. Adenovirus-mediated chronic "hyper-resistinemia" leads to in vivo insulin resistance in normal rats. J Clin Invest 2004;114:224-31.

4. Ruan H, Miles PDG, Ladd CM, et al. Profiling gene transcription in vivo reveals adipose tissue as an immediate target of tumor necrosis factor- $\alpha$. Implications for insulin resistance. Diabetes 2002;51:3176-88.

5. Klover PJ, Zimmers TA, Koniaris LG, Mooney RA. Chronic exposure to interleukin-6 causes hepatic insulin resistance in mice. Diabetes 2003;52:2784-9.

6. Combs TP, Pajvani UB, Berg AH, et al. A transgenic mouse with a deletion in the collagenous domain of adiponectin displays elevated circulating adiponectin and improved insulin sensitivity. Endocrinology 2004;145:367-83.

7. Kirwan JP, Hauguel-De Mouzon S, Lepercq J, et al. TNF- $\alpha$ is a predictor of insulin resistance in human pregnancy. Diabetes 2002;51:2207-13.

8. Mukherjea R, Castonguay TW, Douglass LW, Moser-Veillon P. Elevated leptin concentrations in pregnancy and lactation: Possible role as a modulator of substrate utilization. Life Sci 1999; 65:1183-93.

9. Lewandowski K, Horn R, O'Callaghan CJ, et al. Free leptin, bound leptin, and soluble leptin receptor in normal and diabetic pregnancies. J Clin Endocrinol Metab 1999;84:300-6.

10. Lammert A, Kiess W, Bottner A, Glasow A, Kratzch J. Soluble leptin receptor represents the main leptin binding activity in human blood. Biochem Biophys Res Commun 2001;283: 982-8.

11. Ladyman SR, Grattan DR. Region-specific reduction in leptininduced phosphorylation of signal transducer and activator of transcription-3 (STAT3) in the rat hypothalamus is associated with leptin resistance during pregnancy. Endocrinology 2004; 145:3704-11.

12. Kautzky-Willer A, Pacini G, Tura A, et al. Increased plasma leptin in gestational diabetes. Diabetologia 2001;44:164-72.

13. Retnakaran R, Hanley AJG, Raif N, Connelly PW, Sermer M, Zinman B. Reduced adiponectin concentration in women with gestational diabetes. Diabetes Care 2004;27:799-800.

14. Retnakaran R, Hanley AJG, Raif N, Connelly PW, Sermer M, Zinman B. C-reactive protein and gestational diabetes: the central role of maternal obesity. J Clin Endocrinol Metab 2003; 88:3507-12.

15. Anastasiou E, Alevizaki M, Grigorakis SJ, Philippou G, Kyprianou M, Souvatzoglou A. Decreased stature in gestational diabetes mellitus. Diabetologia 1998;41:997-1001.

16. Jang HC, Min HK, Lee HK, Cho NH, Metzger BE. Short stature in Korean women: A contribution to the multifactorial predisposition to gestational diabetes mellitus. Diabetologia 1998;41:778-83.

17. Sermer M, Naylor D, Gare DJ, et al. Impact of time since last meal on the gestational glucose challenge test. Am J Obstet Gynecol 1994;171:607-16.

18. Davey DA, MacGillivray I. The classification and definition of the hypertensive disorders of pregnancy. Am J Obstet Gynecol 1988;158:892-8.

19. Verhaeghe J, Pintiaux A, Van Herck E, Hennen G, Foidart J-M, Igout A. Placental GH, IGF-I, IGF-binding protein-1, and leptin during a glucose challenge test in pregnant women: Relation with maternal body weight, glucose tolerance, and birth weight. J Clin Endocrinol Metab 2002;87:2875-82.

20. Lee JH, Chan JL, Yiannakouris N, et al. Circulating resistin levels are not associated with obesity or insulin resistance in humans and are not regulated by fasting or leptin administration: Cross-sectional and observational studies in normal, insulin-resistant, and diabetic subjects. J Clin Endocrinol Metab 2003;88:4848-56.

21. Branchtein L, Schmidt MI, Mengue SS, Reichelt AJ, Matos MCG, Duncan BB. Waist circumference and waist-to-hip ratio are related to gestational glucose tolerance. Diabetes Care 1997;20:509-11.

22. Moses RG, Mackay MT. Gestational diabetes: Is there a relationship between leg length and glucose tolerance? Diabetes Care 2004;27:1033-5.

23. Chen H-L, Yang Y, Hu X-L, Yelavarthi KK, Fishback JL, Hunt JS. Tumor necrosis factor alpha mRNA and protein are present in human placental and uterine cells at early and late stages of gestation. Am J Pathol 1991;139:327-35.

24. Coughlan MT, Oliva K, Georgiou HM, Permezel JMH, Rice GE. Glucose-induced release of tumour necrosis factor-alpha from human placental and adipose tissues in gestational diabetes mellitus. Diabetic Med 2001;18:921-7.

25. Radaelli T, Varastehpour A, Catalano P, Hauguel-de Mouzon S. Gestational diabetes induces placental genes for chronic stress and inflammatory pathways. Diabetes 2003;52:2951-8.

26. Krogh-Madsen R, Plomgaard P, Keller P, Keller C, Pedersen BK. Insulin stimulates interleukin- 6 and tumor necrosis factor- $\alpha$ gene expression in human subcutaneous adipose tissue. Am J Physiol Endocrinol Metab 2004;286:E234-8.

27. Chan JL, Blüher S, Yiannakouris N, Suchard MA, Kratzsch J, Mantzoros CS. Regulation of circulating soluble leptin receptor levels by gender, adiposity, sex steroids, and leptin. Diabetes 2002;51:2105-12.

28. Sandhofer A, Laimer M, Ebenbichler CF, Kaser S, Paulweber B, Patsch JR. Soluble leptin receptor and soluble receptor-bound fraction of leptin in the metabolic syndrome. Obes Res 2003;11:760-8

29. Kern PA, Ranganathan S, Li C, Wood L, Ranganathan G. Adipose tissue tumor necrosis factor and interleukin-6 expression in human obesity and insulin resistance. Am J Physiol Endocrinol Metab 2001;280:E745-51.

30. Carey AL, Bruce CR, Sacchetti M, et al. Interleukin-6 and tumor necrosis factor- $\alpha$ are not increased in patients with type 2 diabetes: Evidence that plasma interleukin-6 is related to fat mass and not insulin responsiveness. Diabetologia 2004;47:1029-37.

31. Wu T, Dorn JP, Donahue RP, Sempos CT, Trevisan M. Associations of serum C-reactive protein with fasting insulin, glucose, and glycosylated hemoglobin. Am J Epidemiol 2002;155:65-71.

32. Pradhan AD, Cook NR, Buring JE, Manson JE, Ridker PM. C-reactive protein is independently associated with fasting insulin in nondiabetic women. Arterioscler Thromb Vasc Biol 2003;23: $650-5$.

33. Degawa-Yamauchi M, Bovenkerk JE, Juliar BE, et al. Serum resistin (FIZZ3) protein is increased in obese humans. J Clin Endocrinol Metab 2003;88:5452-5.

34. Volarova de Courten B, Degawa-Yamauchi M, Considine RV, Tataranni PA. High serum resistin is associated with an increase in adiposity but not a worsening of insulin resistance in Pima Indians. Diabetes 2004;53:1279-84.

35. Heilbronn LK, Rood J, Janderova L, et al. Relationship between serum resistin concentrations and insulin resistance in nonobese, obese, and obese diabetic subjects. J Clin Endocrinol Metab 2004;89:1844-8.

36. Winzer C, Wagner O, Festa A, et al. Plasma adiponectin, insulin sensitivity, and subclinical inflammation in women with prior gestational diabetes mellitus. Diabetes Care 2004;27:1721-7. 